\title{
The cosmic center in Early China and its archaic resonances
}

\author{
David W. Pankenier \\ Swedish Collegium for Advanced Study, Lehigh University, \\ 9 West Packer Ave., Bethlehem, PA 18015, USA \\ email: dwp0@lehigh.edu
}

\begin{abstract}
Study of the role of astronomical alignments in shaping the built environment suggests that centuries before establishment of the Empire in 221 BCE, the Chinese had already developed practical, geometrical applications of astronomical knowledge useful in orienting high-value structures. The archaeological record clearly shows this fundamental disposition was already firmly established by the formative period of Chinese civilization in the early 2nd millennium BCE. The cosmological identification of the imperial center with the celestial Pole and an intense focus on the circumpolar 'skyscape' are manifested in the highly symbolic orientation of early imperial capitals. Certain features of this cosmological world-view may have emerged as early as the Neolithic.
\end{abstract}

Keywords. Qin Dynasty, Han Dynasty, astronomical alignment, axis mundi, Neolithic, Yangshao, Puyang

\section{The Qin Dynasty (221-206 BCE) cosmic capital}

Conscious imitation of the celestial patterns is consistent with the skyward orientation of rulership in China from earliest times, ultimately gaining physical expression in the imperial capital. There are well-documented historical instances of such mimicry that go well beyond the cardinal orientation of palaces, city walls, and tombs commonly seen during the so-called Three Dynasties of the 2nd millennium BCE. In 221 BCE the First Emperor of Qin succeeded in annihilating the last of the Warring States and 're-established' the empire of 'all under Heaven' presumed to have been founded two millennia earlier. In addition to arrogating to himself the quasi-divine title of $D i$, 'emperor', Qin Shihuang went to great lengths to demonstrate his legitimacy as universal ruler by reinstituting ancient traditions and rituals. Among the most extraordinary of these efforts was his ambitious building program, which in addition to creating a network of roads and defensive walls, also included the reconstruction of the palaces of conquered states in the Qin capital and the relocation there of their defeated elites.

Of particular interest here, however, is the general plan of the Qin capital of Xianyang. The "Basic Annals of the First Emperor of Qin" in Sima Qian's "The Grand Scribe's Records", Shiji (ca. 100 BCE) (Sima 1959) describes the layout of the imperial center:

"In his [the First Emperor of Qin's] 27th year $(220$ BCE) ... he built the Faithful Palace to the south of the Wei River. Shortly afterward, he renamed the Faithful Palace the [Northern] Culmen Temple to symbolize the celestial Pole. From the [Northern] Culmen Temple a road led to Mount Li, where he built the Forehall of the Sweet Springs Palace. He constructed a corridor to connect it to Xianyang [Palace]." (Nienhauser 1995: 138, transl. modified) 
Subsequently, however:

"The emperor considered Xianyang too overcrowded and the palaces of the former kings too small. [He said:] 'I have heard that King Wen of Zhou [d. 1050 BCE] located his capital at Feng, King Wu [r. 1049-1042 BCE] had his at Hao. The area between Feng and Hao is [suitable to be] the capital of an emperor.' Thereupon he laid out and started to build audience halls on the south bank of the Wei River in the Shanglin Park. He began with the Forehall of the E-pang [Mountainside] Palace, which was five-hundred paces from east to west and fifty spans from north to south. Ten thousand people could be seated on its terraces, and below, flagpoles fifty spans high were erected. From around the Hall elevated passageways led directly to the Southern Mountains. He had a covered causeway built from the E-pang Palace across the Wei River to connect it to Xianyang [Palace], to resemble the Elevated Passageway [constellation in Cassiopeia], which extends from near the celestial Pole across the Milky Way to connect with [lodge] Yingshi Align-TheHALL." (Nienhauser 1995: 148, transl. modified)

The Elevated Passageway (Gedao) was a raised, screened causeway spanning the river which permitted the emperor to move about in secret. Shanglin Park refers to a vast parkland enclosing $14 \mathrm{~km}^{2}$ and containing some nineteen Qin palaces. It was later expanded and filled with exotica by Emperor Wu of Han (r. 141—87 BCE), during Sima Qian's own lifetime. The E-pang Palace is thought to have been the largest palatial complex ever built in China. Begun in $212 \mathrm{BCE}$, only the Forehall of the legendary palace was actually completed before the First Emperor's death. The Han period dimensions given by Sima Qian correspond to $693 \mathrm{~m}$ long $\times 116.5 \mathrm{~m}$ wide. In fact, modern studies of the actual ruin show that its rammed-earth foundation platform still measures an impressive $1,320 \mathrm{~m}$ east to west, $420 \mathrm{~m}$ north to south, and $8 \mathrm{~m}$ in height (Xu 2000: 134; Wu 1997: 108). In the above accounts we see how the Wei River served as the terrestrial analog of the RIVER OF HEAVEn (Milky Way) in relation to the layout of the imperial capital, just as the Yellow River was the terrestrial analog of the Milky Way in the earlier Warring States-period (475-221 BCE) 'field-allocation' scheme of astral-terrestrial correspondences (Pankenier 2005). Note the explicit identification of the capital of Xianyang with the celestial Pole, and the focus on the communication between the Pole and the Celestial Temple, lodge Align-The-Hall. The E-pang Palace is identified with Align-The-Hall or lunar lodges \#13-14 comprising two sides of the Square of Pegasus. It has been shown that in the early period ALIGN-THE-HALL commonly referred to the entire Square of Pegasus, and not merely the western side of the square marked by $\beta$ and $\alpha$ Pegasi (Scheat and Markab), which later became the convention (Pankenier 2009; Ban 2008). This cosmological parallelism, which evokes the celestial source of the imperial charisma and legitimacy, was fundamental in the dynastic ideology of the Chinese Empire (Fig. 1).

The Sanfu huangtu, 'Yellow Plans of the Three Capital Commanderies' (3rd century, with some later interpolations) (Sanfu huangtu 1782), a widely circulated text compiled from Han sources and frequently quoted down through the Song dynasty (960-1279), confirms that this astral-terrestrial correspondence was commonly understood. For example, Zhang Shoujie's (fl. ca. 725-735) commentary to The Grand Scribe's Records quotes from the 'Yellow Plans':

"The 'Yellow Plans of the Three Capital Commanderies' says: 'When the First Emperor of Qin unified all under heaven he made Xianyang his capital. Because he laid out his palace on North Hill, the [circumpolar] Palace of Purple Tenuity resembled the Emperor's Palace. The Wei River ran through the capital, simulating the Milky Way, and the Transverse Bridge crossed [the Wei River] to the south, on the model of [lodge] Ox-Leader ( $\beta$ Cap).' " (Sanfu huangtu, quoted in Shiji, 86.2535)

A similar quotation in the Taiping yulan (72.3b) encyclopedia (10th century) (Taiping yulan 1975) implies that the placing of gates on all four sides of the cardinally 
Figure 1. The Pure Temple (Square of Pegasus) showing its ritually significant polar alignment.

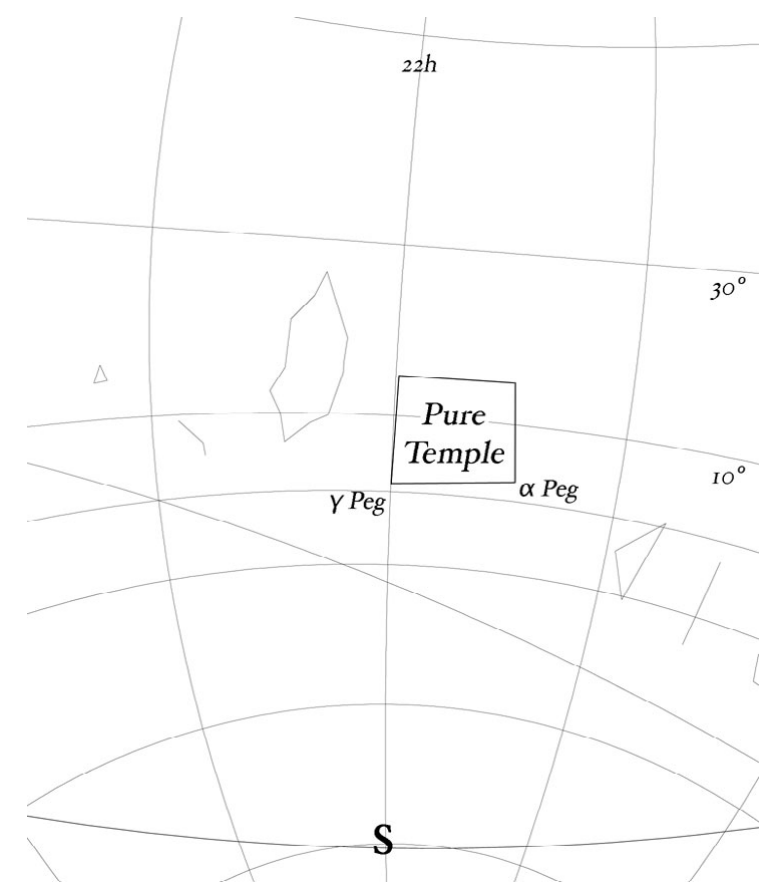

oriented palace followed the pattern of the circumpolar Purple Palace Enclosure (aka, Palace of Purple Tenuity) (Sun \& Kistemaker 1997: 70). From this it is evident that the Qin Elevated Passageway, the analog of the eponymous asterism in CAssiopeIA, was not the only such covered gallery across the Wei River. Judging from the location, the Transverse Bridge's astral correlate was the constellation CELESTIAL Ford $(\delta, o$, $\alpha, \nu, \tau, v, \zeta, \eta, \gamma$ Cyg), which spans the Milky Way near lodge Ox-LEADER marked by ( $\beta$ Cas). Given the First Emperor's fixation with the precedent-setting nature of his universal empire and the monumentality of its physical expression, together with his assumption of the title $D i$ previously reserved for the Supernal Lord, the cosmic parallels he took pains to establish between his capital and the celestial Pole were obviously more than merely symbolic.

But there is more, for in the First Emperor of Qin's time, in late October to early November the brilliant silvery ribbon of the Milky Way arched across the sky from southwest to northeast, precisely like its terrestrial reflex, the Wei River. The PURE TEMPLE (Square of Pegasus) was due south, perpendicular to the horizon and only at this moment capable of fulfilling its ritual function of aligning structures on the Pole (Pankenier 2009; Ban 2008). Here we have the probable explanation for the Qin dynasty's choice of precisely this time to begin the New Year - the highly symbolic moment when Heaven above and the sub-celestial realm below were exactly congruent.

\section{The Han Dynasty (206 BCE-220 CE) cosmic capital}

Following the collapse of the Qin dynasty after a mere fifteen years, the Han founding emperor Gaozu (ca. 250-195 BCE) and his immediate successor, Emperor Hui (r. 195188 BCE) were confronted in their turn with the imperative to establish the legitimacy of the Han Dynasty's assumption of the Mandate of Heaven, the Supernal Lord's numinous charge to a temporal ruler to govern the entire sub-celestial realm. Three centuries later, 
the Eastern Han scholar Zhang Heng (78-139 CE) immortalized the Han founder's lofty ambitions in his 'Rhapsody on the Western Capital' (Xijing fu):

"When our Exalted Ancestor first entered [the Pass], the Five Wefts [Five Planets] in mutual concord migrated into EASTERN WELL [lodge \#22 in Gem] ... Heaven opened his mind [through this sign], and ... when it came time for the Emperor to plan [the siting of his capital], in those intentions he indeed gave thought to the spirits and powers, [and deemed] it appropriate to settle [on Chang'an] as the Celestial City." (transl. Wu 1997: 147; transl. modified)

As Wu Hung points out, the Han founder Gao Zu's symbolic acts were intended to resonate with Zhou dynasty precedents eight centuries earlier. (For the dynastic implications of clusters of the Five Planets, see Pankenier 1995.) Although construction of the new capital was begun by Gaozu in $202 \mathrm{BCE}$ with the building of the Everlasting Palace (weiyang gong), the capital was not actually walled until a decade later, between 194-190 BCE under Emperor Hui. Archaeological studies during the past few decades have revealed how Chang'an appeared during its first century as the Han imperial capital (Wu 1997: 143-187; Xiong 2000: 8-11). Some of those studies allude in passing to the tradition that the idiosyncratic shape of the city walls was inspired by the circumpolar stars, but without discussing archaeological or other evidence. Earlier, Paul Wheatley had published an illustration of his imaginative interpretation of the tradition, at the same time dismissing it as unsupported by archaeological evidence (Wheatley 1971: fig. 26). Wheatley's interpretation, however tentative, is compromised by his evident assumption that the Han Chinese perceived the same configurations of circumpolar asterisms as in the West; namely, two facing dippers, the smaller emptying into the larger. In fact, only Ursa Major, the Northern Dipper, was seen by the Chinese to resemble either a ladle or a carriage, while the stars in Ursa Minor were perceived quite differently (Sun \& Kistemaker 1997). Wheatley's misconception is repeated every time his illustration is reproduced without critical comment (e.g., Wu 1997: 158).

Detailed study by Stephen Hotaling, based on scale drawings of the archaeological excavations, suggested that the contours of the northern wall of the city did indeed reproduce the shape of the NORTHERN DIPPER, while the southern wall represented lunar lodge Southern Dipper (NAndou, $\phi$ Sgr), where the ecliptic intersects the Milky Way (Hotaling 1978: fig. 22). Subsequent investigations confirm the accuracy of Hotaling's reconstruction (Wang 1984a, 1984b; Wu 1997: 150; Liu 2007: 115). In his study, Hotaling quotes an account from the same text cited above, the 'Yellow Plans of the Three Capital Commanderies':

"The south of the city wall was in the shape of the SOUthern Dipper, the north was in the shape of the NorThern Dipper; for this reason until now people still refer to the city wall of the Han capital as the 'DipPer (dou) wall'" (Hotaling 1978, 6; Sanfu huangtu, $1.7 \mathrm{a}-\mathrm{b})$.

In contrast, the east wall of the city was accurately aligned on true north, while the imperial palaces inside the city, such as the famed Everlasting Palace, were rectilinear and cardinally oriented (Liu 2007: 116). Wang Zhongshu (cited in Wu 1997: 156) gives the city wall's impressive dimensions:

"When archaeologists investigated Chang'an's ruins, they found that most of the wall was still exposed above ground. Many wall sections had collapsed, but underground the foundations still remained. According to the two surveys of 1957 and $1962 \ldots$ the total length of the four walls was $25.7 \mathrm{~km}$. ... The city wall, which was built of rammed yellow earth, was over $12 \mathrm{~m}$ high, and the width at its base was 12 to $16 \mathrm{~m}$. ... Outside the city wall was a moat about $8 \mathrm{~m}$ wide and $3 \mathrm{~m}$ deep." 
Figure 2. Stephen Hotaling's proposed reconstruction of the walls of Chang'an (after Hotaling 1978: 39).

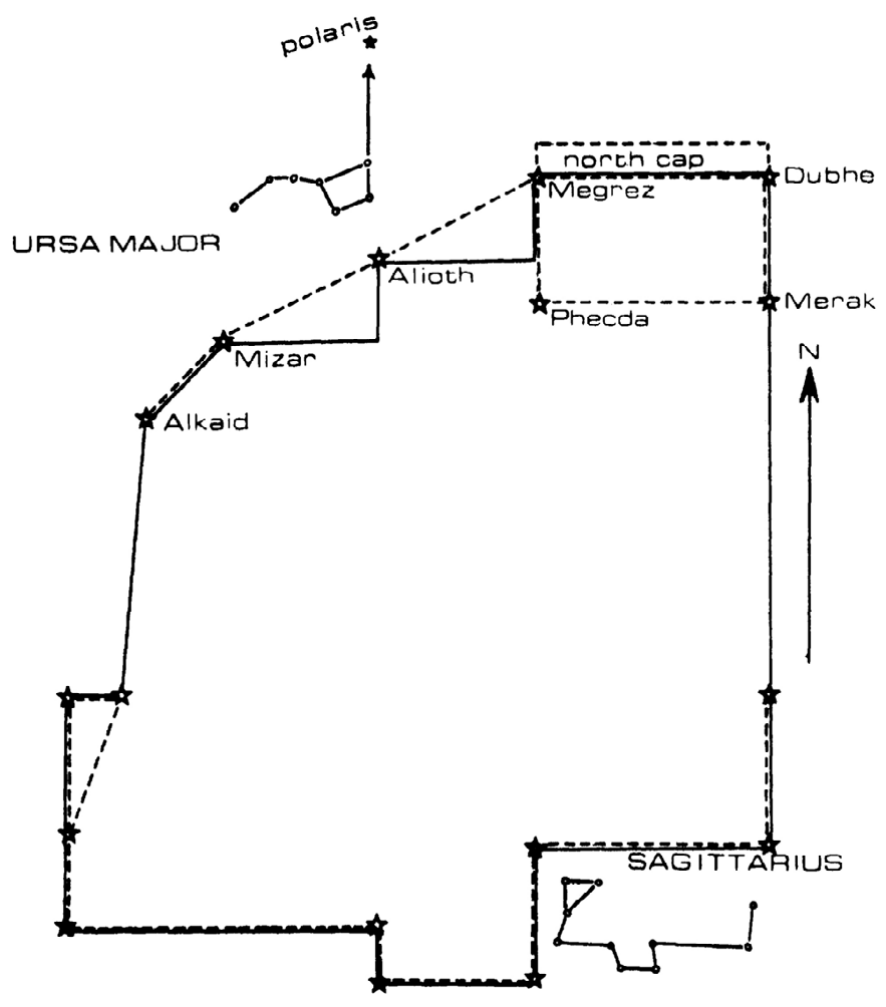

At the upper left in Fig. 2 is Hotaling's inset drawing of Ursa Major showing the stars Dubhe and Merak in the DiPPER's 'bowl' pointing toward Polaris to the north, the present location of the celestial Pole. Hotaling argues that it was this orientation of the DiPPER that was replicated in the outline of the north wall of Chang'an. But there are problems with this interpretation no less serious than with Wheatley's. One is that Polaris was not the Pole Star in the early Han; in fact, the precessing celestial Pole was still some degrees away from Polaris, though in roughly the same general direction with respect to the Dipper. More problematical is that the Southern Dipper in Sagittarius $(\phi, \lambda, \mu, \sigma, \tau, \zeta \mathrm{Sgr})$, whose shape the south wall of Chang'an supposedly replicated, should not lie due south directly behind the Northern Dipper. Instead it should lie well to the north of the southwesterly direction in which the 'handle' portion of the north wall points in Hotaling's reconstruction. Most problematical of all, if the design of the north wall of Chang'an had been conceived as Hotaling suggests, then the fictive Pole such a configuration implies would necessarily lie a considerable distance outside Chang'an to the north, much as would Kochab ( $\beta$ UMi), the brightest star near the Pole in Han times. But placing the celestial Pole, and hence the axis mundi, outside the walls of the imperial capital is completely at odds with the symbolic intentionality at work here, and clearly contradicts the explicit testimony concerning the analogy between the abode of the Supernal Lord and the First Emperor of Qin's capital of Xianyang.

Hotaling's suggested configuration is one that would result from looking up at the Pole, drawing the DIPPER on a surface, and then placing this chart face up on the ground in order to copy the stellar pattern. But proceeding in this fashion actually inverts the orientation of the DIPPER, which is fine if the purpose is merely to draw a chart of the constellation. But to exactly replicate the stellar pattern on the ground one has to place 


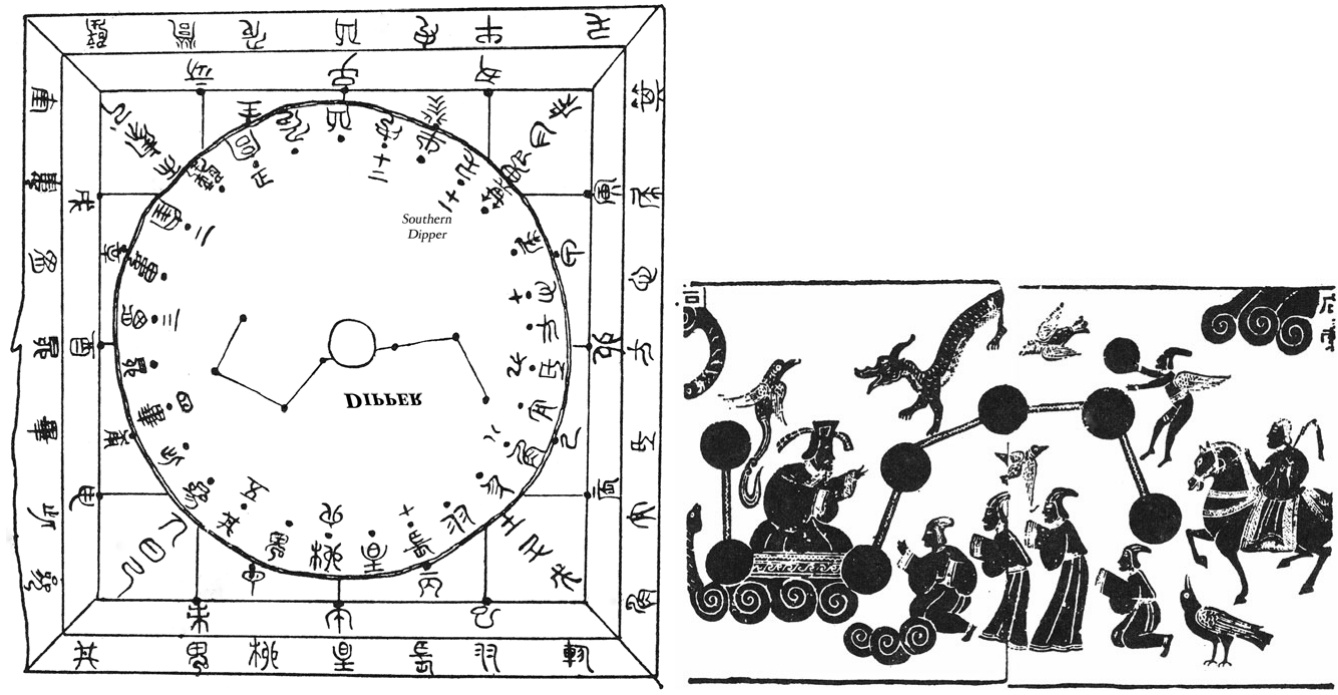

Figure 3. Left: Early Han cosmic board with the Dippen at the center of the rotating 'Heaven Plate', from the tomb of the Marquis of Ru Yin, ca. 168 BCE (after Major 1993: 42). Right: Stone carving from the Wuliang Shrine (ca. 2nd century CE) showing the Supernal Lord driving his heavenly carriage, the DiPPER (after Major 1993: 108).

the sketch of the DiPPER face down, as if the circumpolar stars had floated down to the ground. Only this procedure exactly simulates the configuration of the circumpolar sky on the ground surface, yielding a precise correspondence between the wall of the imperial capital and the Northern Dipper at the Pole.

Thus Hotaling's insight, while ingenious, is conceptually flawed in a crucial respect. The resulting contradictions can easily be resolved, however, if one imagines the DIPPER emptying into Chang'an rather than outside it; that is, configured in a manner identical to its depiction on shi cosmic boards and stone reliefs of the period (Fig. 3). The revision proposed here would simply entail flipping the north-south positions of the pairs of 'bowl' stars, Megrez and Phecda, Dubhe and Merak, with the result that the Pole, and all the 'imperial' stars of UMi like Kochab, 'Heaven's Great August Emperor', would then lie inside the walls of Chang'an (Fig. 4). Admittedly, the position of the last star in the handle of the Dipper, Alkaid ( $\eta$ UMa), would then look out of place in Hotaling's depiction of the north wall, but it was the reconstruction of precisely this section of the wall that posed the greatest problems, leading to Hotaling's characterization of this corner as tentative.

Significantly, this modification of Hotaling's reconstruction also resolves the seemingly problematical identification in Fig. 2 of the south wall of Chang'an with the SouTHERN DipPer ( $\phi$ Sgr), because now the SOUTHERn DIPPER's location vis à vis the north wall's NORTHERn DIPPER corresponds to its true position in the sky. (On the Han cosmograph shown in Fig. 3, the SOUTHERn Dipper is identified by the character 'DipPeR' in the 8-o'clock position.) The practice of keying determinative stars of the lodges to the stars of the DIPPER was already very old by the Han dynasty. In this case the linkage was between the determinative star of the Southern Dipper ( $\phi$ Sgr), and Alioth ( $\epsilon$ UMa) (Needham 1959: 233; Feng 2007: 276). Our proposed configuration explains the curious fact, which confounded Hotaling, that the moat along the south wall of Chang'an is said to have pierced the 'scoop' of the SOUTHERN DIPPER where it protruded from the wall containing the gate through which the main north-south thoroughfare passed. Given the 


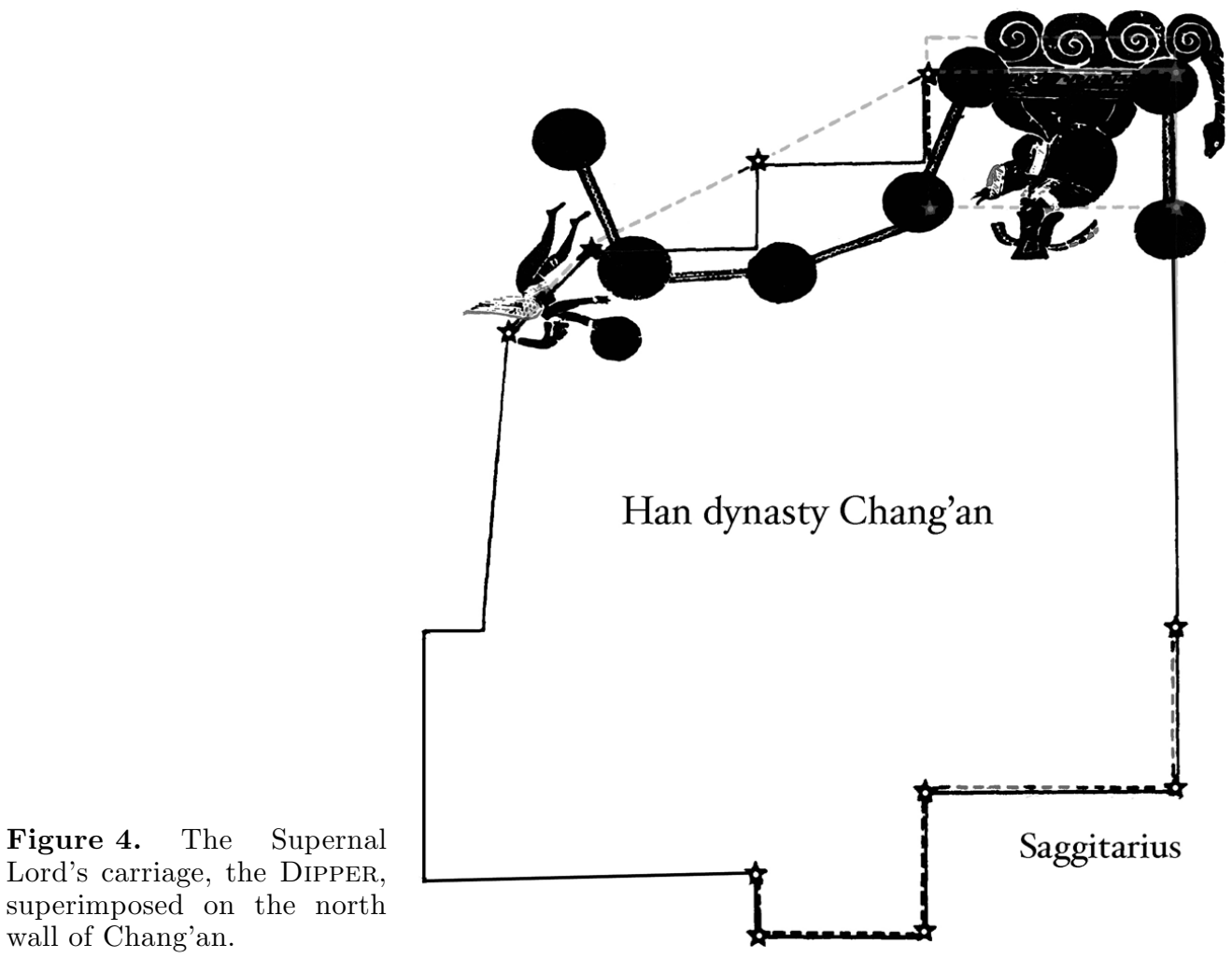

precedent established by the First Emperor of Qin, who exploited the Wei River's course so that it would actually flow through the capital just south of his Xianyang palace, and given the fact of the SOUTHERN DIPPER's actual location in Sagittarius within the 'silvery river' of the Milky Way, this curious feature of Chang'an's south wall now also fits the pattern.

Now, what could be the rationale for representing the DIPPER as a mirror image of the figure we are used to seeing in the sky? One possible reason is in the design of a celestial globe. But in the late 3rd century BCE the articulation of the concept of a spherical heaven was still some centuries in the future. It is doubtful whether the diviners who made astrological devices like the shi cosmic board, or the engineers who built Chang'an's walls, would have imagined themselves looking down on the Pole from a vantage point in the realm of the formless beyond it; that is, imagining themselves outside the cosmos looking over the shoulder of the Supernal Lord. Such a perspective does not appear until celestial globes were produced centuries later, and surviving star maps from the Tang dynasty do not depict the DIPPER this way. This kind of depiction is hardly to be expected at this early date. The principal rationale is, I imagine, as the Appended Commentary to the Book of Changes says: "Heaven suspends images, to manifest the propitious and the inauspicious, and the Sage makes of himself their semblance." That is, they were not about mapping the circumpolar sky, but about creating a simulacrum of the celestial images so that the capital would actually embody the numinous power of the cosmic center. As Stanley Tambiah has observed, "One of the principal implications of the cosmological model is that the center ideologically represents the totality and embodies the utility of the whole" (Tambiah, 1985: 266). 


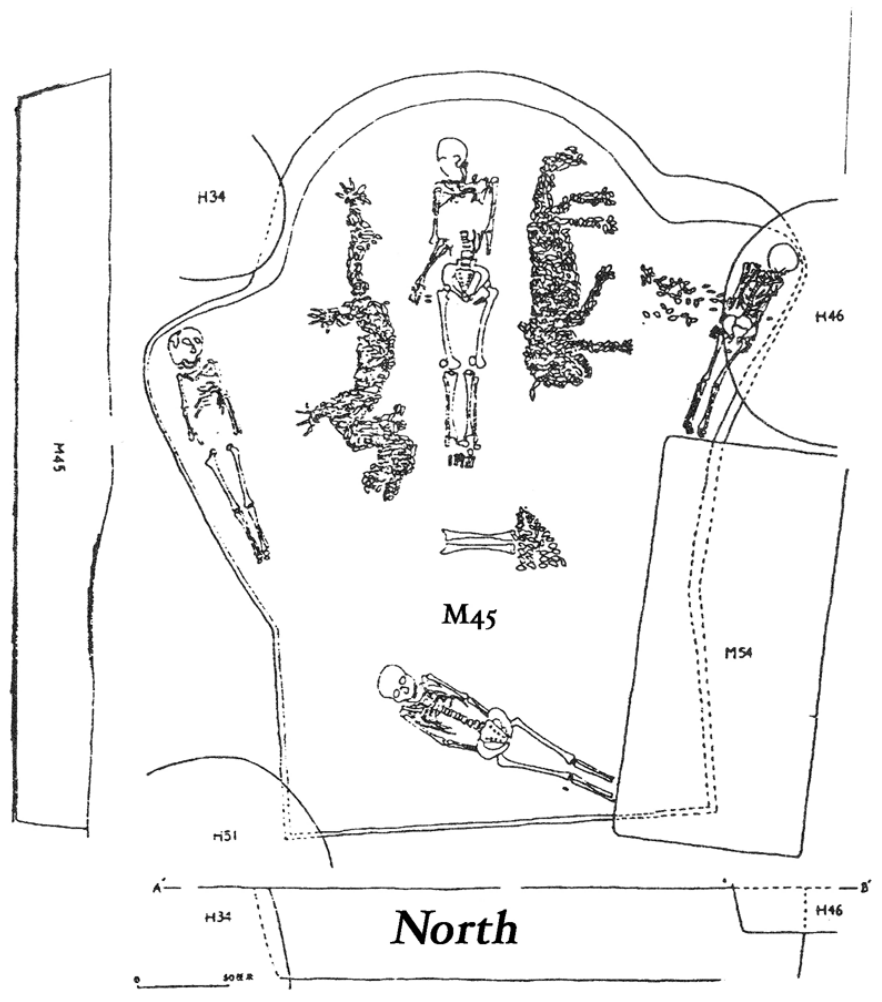

Figure 5. 4th millennium BCE 'cosmo-priest's' tomb M45, at Puyang, Xishuipo, Henan.

\section{A Neolithic precedent?}

One of the most extraordinary achaeological finds in China in recent memory was the 1987 discovery of a 'cosmologically' inspired Yangshao culture burial at Puyang, Xishuipo in Henan Province dating from the late 4th millennium BCE (Fig. 5). The elite individual buried in the center of the unprecedentedly large, cardinally oriented grave, thought to be a tribal chief and shaman or cosmo-priest, is aligned with his feet to the north and head to the south, and accompanied by three sacrificial victims. What makes the find sensational, however, are the mussel shell mosaics carefully laid out beside the chief occupant of the tomb - a dragon (or alligator) to his east, a tiger to his west, and a third figure comprising a mosaic triangle and two human tibias at his feet in the north.

Similar, if less elaborately arranged mosaics have been found in associated burials several meters due south, including one containing the skeleton of the individual whose lower legs are missing and presumed to be those in the main burial. Another adds mosaics of a deer and a spider accompanying a dragon and tiger. Still another depicts a human figure sitting astride a dragon. These Yangshao burials have excited great interest because of the cosmological associations evoked by the animal familiars accompanying the tomb occupant. This is so because the directions associated with the dragon and tiger are precisely the same as in the correlative cosmology of some 4,000 years later, with the Cerulean Dragon to the east (the constellation comprising Vir-Sco) and White Tiger to the west (corresponding to And-Ori). The third image at the 'shaman's' feet in the north has been taken to be a representation of the NorThern Dipper. Not surprisingly, the whole composition has been interpreted by some as a map of the heavens.

Inevitably, that interpretation of the burials has occasioned much debate. Despite the very early date some see in tomb M45 an actual sky map, others a pictorial representation 
of a cosmological world-view, some as simply a shamanic burial. Our purpose here is not to take a definite position in favor of one or the other of these hypotheses, but merely to consider certain salient facts about the orientations of the mosaics and their potential cosmological associations. First, there is no denying that the head-to-head and tail-to tail-placement of the iconic figures, their creaturely identities, as well as the cardinal arrangement of all three images, are consistent with the well-documented conventional cosmological correlations of the mid- to late 1st millennium BCE. Second, no comparable pictorial composition has been found earlier than the strikingly similar depiction on the lacquer hamper lid from the tomb of the Marquis Yi of Zeng, dating from ca. 433 BCE (Chen \& Xi 1993: 47ff.; Feng 2007: 277). Third, examples do exist of dragon glyphs and a bronze dragon-shaped vessel with astral imagery from the Shang period in the late-2nd millennium BCE (Pankenier 2011). Fourth, the opposition between the principal asterisms of the dragon and tiger (Sco \& Ori) is singled out in etiological myth as seasonally significant. It is precisely these stellar configurations plus the DIPPER that are stressed in classical texts (e.g., the Gong Yang Commentary to the Spring and Autumn Annals) as the three Great Sky-Signs (da chen), or crucially important seasonal signposts. Fifth, preternatural control over time and space is metaphorically represented as 'riding the dragon' in the Book of Changes and in early iconography. Sixth, and most interesting from the perspective of the preceding discussion of circumpolar mimicry, the DIPPER-like object placed at the feet of the tomb occupant is depicted in precisely the same orientation as in the graphic representations we saw above from the Han dynasty; that is, as a mirror image of the DIPPER in the sky. Not only that, but just as in the case of the city wall of Chang'an where the orientation of the NorTHERn and SOUTHERn Dippers are at odds, the orientation of the DIPPER in the tomb is similarly inconsistent with respect to the other two 'constellation' images, a sign that, conceptually, the representational motives are not the same.

If we consider that a chart of the heavens is not a portrayal of something that can actually be seen at a given moment in time, but as an imaginative composite of the totality of skyscapes that pass overhead, then given the early date it seems hardly plausible that the Puyang burial could have been intended as a map of the heavens in anything like the modern sense. Instead, what we have in this tomb is a representation of the prime importance of the principal constellations in their timekeeping roles, and allusion to their 'management' by certain uniquely empowered individuals closely connected with rulership. The DIPPER, in particular, is supremely emblematic of the mysterious power at the center of the sky to which the cosmo-priest paid homage in life and would presumably continue to do after death. Its depiction in mirror image may, like shamanic imagery elsewhere, be specifically evocative of this magical relationship. As in the parallel case of Han Chang'an, the numinous power of the DiPPER is being conjured up by placement in the tomb of this Yangshao chieftain. Despite the temporal gap, the parallels between the cosmo-priest's tomb and the grand cosmovision invoked by the layout of early imperial capitals (at the time thought to be evocative of a remembered past) point to a cultural continuity spanning many centuries.

\section{Conclusion}

The ancient Chinese were intensely interested in the circumpolar region, and especially in orientation toward the mysteriously vacant Pole itself, from the very beginning of Chinese civilization (Pankenier 2004). Study of the role of astronomical alignment in shaping the built environment shows that centuries before the emergence of the 'Celestial Empire' the Chinese had already developed practical, geometrical applications of 
astronomical knowledge. A case in point is the sophisticated use by the mid-1st millennium BCE of the parallel sides of the PURE TEMPLE (Great Square of Pegasus) to assure a ritually correct polar alignment of high value structures (Pankenier 2009; Ban 2008). Clear evidence exists of the identification of the imperial center with the celestial Pole in the form of iconography and the layout of early imperial capitals as simulacra of the circumpolar skyscape. Parallels with unique features of this early imperial cosmovision may be traceable to the late-Neolithic, suggesting a surprising degree of historical continuity of cosmological conceptions.

\section{References}

Ban D.-W. (Pankenier, D. W.) 2008, Ziran kexueshi yanjiu 27(3), 281.

Chen C.-Y. \& Xi Z.-Z. 1993, in C. L. N. Ruggles \& N. J. Saunders (eds), Astronomies and Cultures, University Press of Colorado, Niwot, p. 32.

Feng S. 2007, Zhongguo tianwen kaoguxue, Zhongguo shehui kexue, Beijing.

Hotaling, S. J. 1978, Toung Pao 64(1-3), 1.

Liu Q.-Z. 2007, Early China 31, 113.

Major, J. S. 1993, Heaven and Earth in Early Han Thought, State University of New York Press, Albany.

Needham, J. 1959, Science and Civilisation in China, Vol. 3: Mathematics and the Science of the Heavens and the Earth, Cambridge University Press, Cambridge.

Nienhauser, W. H. (ed.) 1995, Ssu-ma Ch'ien. The Grand Scribe's Records, Vol. 1: The Basic Annals of Pre-Han China, Indiana University Press, Bloomington.

Pankenier, D. W. 1995, Early China 20, 121.

Pankenier, D. W. 2004, Journal of the American Oriental Society 124(2), 211.

Pankenier, D. W. 2005, in J. W. Fountain \& R. M. Sinclair (eds), Current Studies in Archaeoastronomy: Conversations across Time and Space, Carolina Academic Press, Durham NC, p. 499.

Pankenier, D. W. 2009, Locating True North in Ancient China. Cosmology Across Cultures 409, 128.

Pankenier, D. W. 2011, Astronomy in the Age of Dragons. In Proceedings of SEAC 17 (2009), British Archaeological Reports, Archaeopress, Oxford.

Sanfu huangtu 1782, Sanfu huangtu (Yellow Plans of the Three Capital Commanderies, ca. 3rd to 6th century), Siku quanshu, 1782 edn.

Sima Q. 1959, Shiji (The Grand Scribe's Records), Zhonghua shuju, Beijing.

Sun X.-C. \& Kistemaker, J. 1997, The Chinese Sky during the Han: Constellating Stars and Society, E. J. Brill, Leiden.

Taiping yulan 1975, Taiping yulan, 1975 rpt., Pingping chuban she, Taipei.

Tambiah, S. J. 1985, Culture, Thought and Social Action: an Anthropological Perspective, Harvard University Press, Cambridge MA.

Wang Z.-S. 1984a, Han Civilization, Yale University Press, New Haven.

Wang Z.-S. 1984b, Handai kaoguxue gaiyao, Zhonghua, Beijing.

Wheatley, P. 1971, The Pivot of the Four Quarters: a Preliminary Enquiry into the Origins and Character of the Ancient Chinese City, Edinburgh University Press, Edinburgh.

Wu H. 1997, Monumentality in Early Chinese Art and Architecture, Stanford University, Stanford.

Xiong, V. C. 2000, Sui-Tang Chang'an: a Study in the Urban History of Medieval China, Center for Chinese Studies, University of Michigan, Ann Arbor.

Xu W.-M. 2000, Qin ducheng yanjiu, Shaanxi renmin jiaoyu, Xi'an. 